
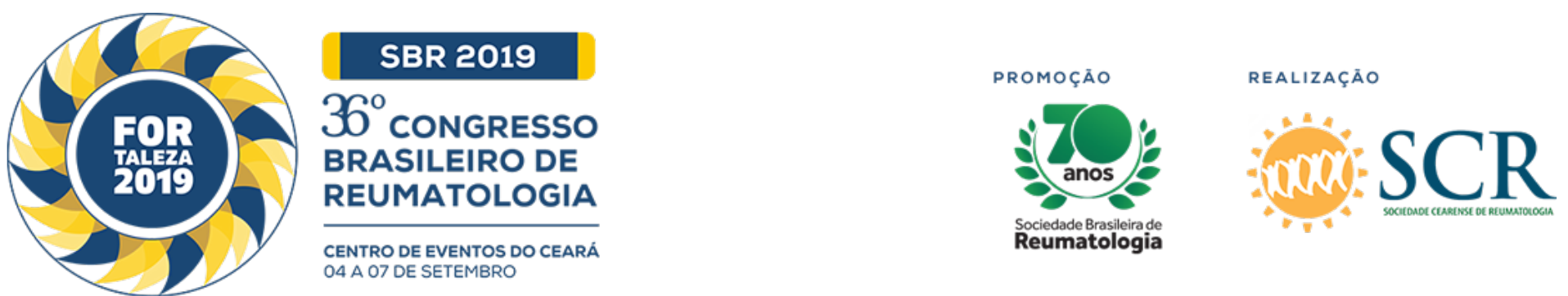

\title{
FAMILY DYSFUNCTIONS ASSESSMENT IN SYSTEMIC LUPUS ERYTHEMATOSUS USING FAMILY APGAR
} QUESTIONNAIRE.

Marcela Braga Sampaio (Universidade Estadual do Ceará (UECE), Fortaleza, CE, Brasil), Luiz Valério Costa Vasconcelos (Universidade de Fortaleza (UNIFOR), Fortaleza, CE, Brasil), John Kennedy Torres de Alencar (Universidade de Fortaleza (UNIFOR), Fortaleza, CE, Brasil), Igor Quezado Araújo de Andrade (Universidade de Fortaleza (UNIFOR), Fortaleza, CE, Brasil), Lysiane Maria Adeodato Ramos (Hospital Geral de Fortaleza (HGF), Fortaleza, CE, Brasil), Rejane Maria Rodrigues de Abreu Vieira (Hospital Geral de Fortaleza (HGF), Universidade Estadual do Ceará (UECE) e Universidade de Fortaleza (UNIFOR), Fortaleza, CE, Brasil)

\section{BACKGROUND}

Systemic Lupus Erythematosus (SLE), is a chronic inflammatory disease, which symptoms can occur in several organs, can often cause several limitations to patients life, and require special care, especially in the phases of pathology activity. This situation can occasionally create a disturbance within the family environment. A family APGAR questionnaire is an instrument used as a screening test to identify family dysfunctions. It allows the identification of the family, from the perspective of its members, as a psychosocial resource or as a deficit social support and possible stressor. It adapted to the Brazilian context, and scores range from 0 to 10 points. The index of 7 to 10 indicates a highly functional family, the index of 4 to 6 suggests a family moderately dysfunctional, and the 0 to 3 index suggests a severely dysfunctional family. The objective of this study was to evaluate the APGAR family of patients with SLE.

\section{MATERIALS AND METHODS}

A quantitative cross-sectional survey was carried out at the Rheumatology Service of a public hospital, with the application of the family APGAR questionnaire. The Ethics and Research Committee approved the study. All participants signed a TCLE.

\section{RESULTS}

We interviewed 48 patients with SLE. The majority of patients interviewed were female (95.8\%), with a mean age of $39.35 \pm 13.09$. The mean of the total score of the family APGAR was $8.35 \pm 2.38$. Regarding the identification of family dysfunctions, $85.5 \%$ of the patients interviewed classified as having highly functional families, and only $6.2 \%$ as having severely dysfunctional families. About the housing arrangements, most patients (31.3\%) live alone with their spouses and descendants. Apropos of the family constitution, the majority of respondents are married (54.2\%), have 0 to 1 children (60.4\%) and most have 2 to 4 siblings (37.5\%).

\section{CONCLUSION}

Patients with SLE, for the most part, have highly functional families when evaluated by the family APGAR. 